\title{
In vitro antimicrobial effects of aztreonam, colistin, and the 3-drug combination of aztreonam, ceftazidime and amikacin on metallo- -lactamase-producing Pseudomonas aeruginosa Shigeharu Oie, Yumi Fukui, Masaya Yamamoto, Yuki Masuda and
} Akira Kamiya*

Address: Department of Pharmacy, Yamaguchi University Hospital, Ube, Japan

Email: Shigeharu Oie - oie-ygc@umin.ac.jp; Yumi Fukui - h063eb@yamaguchi-u.ac.jp; Masaya Yamamoto - f081eb@yamaguchi-u.ac.jp; Yuki Masuda - yuki54@hiroshima-u.ac.jp; Akira Kamiya* - akira-ygc@umin.ac.jp

* Corresponding author

Published: 10 August 2009

BMC Infectious Diseases 2009, 9:123 doi:10.1/86/147|-2334-9-123

This article is available from: http://www.biomedcentral.com/147/-2334/9//23

(C) 2009 Oie et al; licensee BioMed Central Ltd.

This is an Open Access article distributed under the terms of the Creative Commons Attribution License (http://creativecommons.org/licenses/by/2.0), which permits unrestricted use, distribution, and reproduction in any medium, provided the original work is properly cited.
Received: 27 January 2009

Accepted: 10 August 2009

\begin{abstract}
Background: There are limited choice of antimicrobial agents to treat infection with metallo- lactamase-producing Pseudomonas aeruginosa. We evaluate the antimicrobial effects of aztreonam alone, colistin alone and the 3-drug combination of aztreonam, ceftazidime and amikacin on 23 strains of metallo- -lactamase-producing $P$. aeruginosa by time-killing tests.

Methods: Strains used were from different hospitals in Japan and had different pulse-field gel electrophoresis patterns by restriction with Spel. The minimum inhibitory concentrations of II antimicrobial agents (piperacillin, piperacillin/tazobactam, imipenem, meropenem, aztreonam, ceftazidime, amikacin, tobramycin, arbekacin, ciprofloxacin and colistin) were determined using the agar dilution test. The effects of aztreonam, colistin and the combination of aztreonam, ceftazidime and amikacin were determined by time-killing studies.

Results: Bacteriostatic effects after 6 hours of drug exposure were observed in 12 strains (52.2\%) of 23 strains of metallo- -lactamase-producing $P$. aeruginosa with $48 \mathrm{mg} / \mathrm{l}$ aztreonam, in 19 strains (82.6\%) with the 3 -drug combination of $16 \mathrm{mg} / \mathrm{l}$ aztreonam, $16 \mathrm{mg} / \mathrm{l}$ ceftazidime, and $4 \mathrm{mg} / \mathrm{l}$ amikacin, and in 23 strains ( $100 \%$ ) with $2 \mathrm{mg} / \mathrm{l}$ colistin. Bactericidal effects after $6 \mathrm{~h}$ drug exposure were observed in I strain (4.3\%) with $48 \mathrm{mg} / \mathrm{l}$ aztreonam, in 8 strains (30.4\%) with the 3-drug combination and in all 23 strains (100\%) with $2 \mathrm{mg} / \mathrm{l}$ colistin.
\end{abstract}

Conclusion: Evaluation of in vitro antimicrobial effects on metallo- -lactamase-producing $P$. aeruginosa revealed relatively good effects of the 3-drug combination of aztreonam, ceftazidime and amikacin and marked effects of colistin.

\section{Background}

Pseudomonas aeruginosa is a major bacterium causing nosocomial infection, and the development of multidrug resistance has become a problem [1-7]. Since metallo- - lactamase (MBL)-producing $P$. aeruginosa is often resistant not only to all -lactams, but also aminoglycosides, and fluoroquinolones, there are often no drugs to treat infection with this bacterium [8-10]. In addition, no extended 
survey involving a series of human infections with MBLpositive isolates has been performed to determine the optimal treatment. Thus, appropriate therapy for those infections remains unknown [11].

We previously reported the effects of the 3-drug combinations of aztreonam, ceftazidime and amikacin or aztreonam, piperacillin and amikacin on 7 strains of multidrug-resistant $P$. aeruginosa [8-10]. In this study, to confirm the effectiveness of the 3-drug combinations, we evaluated the effects on a total of 23 strains of MBL-producing $P$. aeruginosa isolated in 23 hospitals in Japan in comparison with the effects of aztreonam or colistin alone.

\section{Methods \\ Bacterial strains}

Among P. aeruginosa strains sent from hospitals in Japan to the Japanese National Institute of Infectious Disease for detailed examination between January 2007 and July 2008, MBL-producing $P$. aeruginosa strains were screened, and MBL typing was performed according to the method of Shibata et al [12]. All 23 strains (one strain/hospital) of MBL-producing $P$. aeruginosa isolated during this period were donated by the Department of Bacterial Pathogenesis and Infection Control, National Institute of Infectious Disease, and used for the experiments.

\section{Pulsed-field gel electrophoresis}

The high-molecular-weight chromosomal DNA was prepared according to the method of Murray et al [13], and the DNA sample in a small slice of an agarose plug in 200 $\mu \mathrm{l}$ of reaction buffer was digested with $30 \mathrm{U}$ SpeI (New England Bio Labs, USA). Pulsed-field gel electrophoresis was carried out with the Bio-Rad Gene Path system (BioRad, USA) in a $1 \%$ agarose gel in $0.5 \times$ TBE buffer at $14^{\circ} \mathrm{C}$ with a linear ramp time of 1 to $23 \mathrm{~s}$ over a period of 18.5 $\mathrm{h}$. Thereafter, the gels were stained with ethidium bromide and photographed.

\section{Susceptibility tests using agar dilution methods}

The minimum inhibitory concentrations (MICs) were determined after $18 \mathrm{~h}$ of incubation at $37^{\circ} \mathrm{C}$ by dilution on Sensitivity Disc Agar-N (Nissui Pharmaceuticals, Tokyo, Japan). The following antimicrobial agents were tested: piperacillin, piperacillin/tazobactam (Toyama Chemicals, Tokyo, Japan), imipenem, amikacin (Banyu Pharmaceuticals, Tokyo, Japan), meropenem (Dainippon-Sumitomo Pharmaceuticals, Tokyo, Japan), aztreonam (Eisai Co., Tokyo, Japan), ceftazidime (Glaxo Japan Co., Tokyo, Japan), tobramycin (Shionogi Pharmaceuticals, Tokyo, Japan), arbekacin (Meiji Seika Co., Tokyo, Japan), ciprofloxacin (Bayer Japan Co., Tokyo, Japan) and colistin (Wako Junyaku Co., Osaka, Japan). These antibiotics except for ciprofloxacin were provided in the form of a freeze-dried amorphous powder. The inocula $\left(10^{4} \mathrm{col}-\right.$ ony-forming units [cfu]/spot) were plated using a multipoint inoculator (Sakuma Co., Tokyo, Japan). The MIC was defined as the lowest drug concentration that inhibited visible growth. P. aeruginosa IFO 3919 was used as the reference strain. The drug concentrations (breakpoints) were set as follows: piperacillin, $64 \mathrm{mg} / \mathrm{l}$; imipenem and meropenem, $8 \mathrm{mg} / \mathrm{l} ;$ aztreonam and ceftazidime, $16 \mathrm{mg} / \mathrm{l}$; amikacin, tobramycin and arbekacin, $4 \mathrm{mg} / \mathrm{l}$; ciprofloxacin and colistin, $2 \mathrm{mg} / \mathrm{l}$. Breakpoints used for all agents (except for amikacin, tobramycin, arbekacin and colistin) were according to the National Committee for Clinical Laboratory Standards (NCCLS) criteria [14]. The concentration of amikacin and tobramycin was $4 \mathrm{mg} / \mathrm{l}$, which is lower than the criteria of the NCCLS. This was because in Japan, the routine dose of these agents is lower (ex. in the case of amikacin, 200-400 $\mathrm{mg} /$ day in one to two divided doses) than that in Western countries. The concentration of colistin used was according to a report by Soussy et al [15].

\section{Drug effects in killing tests}

Killing experiments were carried out to evaluate the bactericidal activities of $48 \mathrm{mg} / \mathrm{l}$ aztreonam, $2 \mathrm{mg} / \mathrm{l}$ colistin, and the 3-drug combination of $16 \mathrm{mg} / \mathrm{l}$ aztreonam, 16 $\mathrm{mg} / \mathrm{l}$ ceftazidime and $4 \mathrm{mg} / \mathrm{l}$ amikacin. The final concentration of the log-phase inocula was approximately $10^{5}$ $10^{7} \mathrm{cfu} / \mathrm{ml}$ [16-19]. Viability was determined based on bacterial counts at 2, 4, 6 and $24 \mathrm{~h}$ after incubation with drugs at $37^{\circ} \mathrm{C}$ by plating $500 \mu \mathrm{l}$ of serial dilutions from each tube onto trypticase soy agar plates followed by incubation of the plates at $37^{\circ} \mathrm{C}$ for 24 to $48 \mathrm{~h}$. In a preliminary experiment, drug carryover was ruled out by plating samples of a bacterial suspension containing $2 \times 10^{2}-4 \times$ $10^{2} \mathrm{cfu} / \mathrm{ml}$ in the presence or absence of antimicrobial agents alone or in combination. We also carried out preliminary killing tests with the 3-drug combination of 16 $\mathrm{mg} / \mathrm{l}$ aztreonam, $16 \mathrm{mg} / \mathrm{l}$ ceftazidime and $4 \mathrm{mg} / \mathrm{l} \mathrm{ami-}$ kacin, of $16 \mathrm{mg} / \mathrm{l}$ aztreonam, $64 \mathrm{mg} / \mathrm{l}$ piperacillin and 4 $\mathrm{mg} / \mathrm{l}$ amikacin, and of $16 \mathrm{mg} / \mathrm{l}$ aztreonam, $64 \mathrm{mg} / \mathrm{l}$ piperacillin/4 mg/l tazobactam and $4 \mathrm{mg} / \mathrm{l}$ amikacin on 23 strains of MBL-producing $P$. aeruginosa. As a result, the viable cell count at $4 \mathrm{~h}$ after drug addition decreased to $1 / 100$ or less of the initial count in 12 strains with aztreonam, ceftazidime and amikacin, 6 strains with aztreonam, piperacillin and amikacin and 4 strains with aztreonam, piperacillin/tazobactam and amikacin. Thus, the combination of aztreonam, ceftazidime and amikacin was the most effective, and therefore, the in vitro antimicrobial effects of this drug combination were evaluated.

Bactericidal activity was defined as a $\leq 3 \log _{10} \mathrm{cfu} / \mathrm{ml}$ decrease in the starting inoculum. A bacteriostatic effect was defined as any decrease in the viable count from the starting inoculum [17]. 


\section{Data analysis}

In the killing tests, the effects on the 23 strains of MBLproducing $P$. aeruginosa were compared among aztreonam alone, colistin alone and the three-drug combination of aztreonam, ceftazidime and amikacin using the KruskalWallis test based on the decrease in the viable count from the initial count at 2, 4, 6 and $24 \mathrm{~h}$ after drug addition.

\section{Results}

Of the 23 MBL-producing $P$. aeruginosa strains, 1 strain (strain no. 7) was $b l a_{\mathrm{VIM}-2}$, and the other 22 strains were $b l a_{\mathrm{IPM}-1}$ by MBL typing. All 23 strains tested were confirmed to differ in their DNA pattern by pulsed-field gel electrophoresis. Concerning differences in the PFGE pattern, a one band difference was observed in 10 strains of 5 groups, 2-3 band differences in 5 strains of 2 groups, and more than 3 band differences in the other strains. Table S1 [additional file 1] shows the MICs of the 11 drugs against the 23 strains of MBL-producing $P$. aeruginosa. The MIC of piperacillin was $\leq 64 \mathrm{mg} / \mathrm{l}$ in $16(69.6 \%)$ of the 23 strains. The MIC of piperacillin/tazobactam was $\leq 64 \mathrm{mg} /$ 1 in $20(87.0 \%)$, that of aztreonam was $\leq 16 \mathrm{mg} / \mathrm{l}$ in 13 $(56.5 \%)$ and that of colistin was $\leq 2 \mathrm{mg} / \mathrm{l}$ in all 23 strains. However, the MICs of the other antimicrobial agents were high in most strains.

Aztreonam ( $48 \mathrm{mg} / \mathrm{l})$ had bacteriostatic effects on 43.5$56.5 \%$ of the strains but bactericidal effects on only 0$4.3 \%$ at $2-24 \mathrm{~h}$ after its addition (Table 1, Figure 1 ). The 3 -drug combination of aztreonam (16 mg/l), ceftazidime $(16 \mathrm{mg} / \mathrm{l})$ and amikacin $(4 \mathrm{mg} / \mathrm{l})$ had bacteriostatic effects on $69.6-82.6 \%$ of the strains and bactericidal effects on $8.7-39.1 \%$ at $2-24 \mathrm{~h}$ after their addition (Table 2, Figure $2)$. On the other hand, colistin ( $2 \mathrm{mg} / \mathrm{l})$ exhibited bactericidal effects on all strains $(100 \%)$ at $2-24 \mathrm{~h}$ after its addition (Table 3, Figure 3). Kruskal-Wallis tests showed significant decreases in the viable cell count at 2, 4, 6 and $24 \mathrm{~h}$ after the addition of colistin (Figure 3) compared with aztreonam alone (Figure 1) or the 3-drug combination of aztreonam, ceftazidime and amikacin (Figure 2).

Table I: Antimicrobial effects of aztreonam (48 mg/l) against 23 strains of metallo- -lactamase-producing $P$. aeruginosa

\begin{tabular}{ccc}
\hline & \multicolumn{2}{c}{ No. of strains (\%) showing effects ${ }^{\mathrm{a}}$} \\
\cline { 2 - 3 } Time of exposure (h) & Bacteriostatic effects & Bactericidal effects \\
\hline 2 & $13(56.5)$ & $0(0)$ \\
4 & $10(43.5)$ & $0(0)$ \\
6 & $12(52.2)$ & $1(4.3)$ \\
24 & $11(47.8)$ & $1(4.3)$ \\
\hline
\end{tabular}

aBacteriostatic effects, any decrease in the viable count from the starting inoculum; bactericidal effects, $\geq 3 \mathrm{log} \mathrm{cfu} / \mathrm{ml}$ decrease in the starting inoculum.
Table 2: Antimicrobial effects of the 3-drug combination of aztreonam (16 mg/l), ceftazidime (16 mg/l) and amikacin $(4 \mathrm{mg} /$ I) against 23 strains of metallo- -lactamase-producing $P$. aeruginosa

\begin{tabular}{ccc}
\hline & \multicolumn{2}{c}{ No. of strains (\%) showing effects ${ }^{\mathrm{a}}$} \\
\cline { 2 - 3 } Time of exposure (h) & Bacteriostatic effects & Bactericidal effects \\
\hline 2 & $18(78.3)$ & $2(8.7)$ \\
4 & $16(69.6)$ & $5(21.7)$ \\
6 & $19(82.6)$ & $7(30.4)$ \\
24 & $16(69.6)$ & $9(39.1)$
\end{tabular}

aBacteriostatic effects, any decrease in the viable count from the starting inoculum; bactericidal effects, $\geq 3 \mathrm{log} \mathrm{cfu} / \mathrm{ml}$ decrease in the starting inoculum.

\section{Discussion}

No hydrolysis of aztreonam by MBL has been reported, and studies using an animal model of pneumonia infection with a VIM-2-positive $P$. aeruginosa isolate showed that a high-dose of aztreonam reduced the bacterial load and may be a useful drug $[20,21]$. Aztreonam is negligibly toxic and can be administered at high doses. After highdose administration, a blood concentration three times the breakpoint can be achieved [22].

A 2-drug combination of a -lactam antibiotic and an aminoglycoside antibiotic was reported to be effective against $P$. aeruginosa $[16,19,23-27]$. However, for multidrug-resistant $P$. aeruginosa, 3-drug combinations such as that of aztreonam, ceftazidime and amikacin rather than 2-drug combinations were shown to exhibit more marked in vitro antimicrobial effects [8,9]. Such observation is based on experiments in one country. In addition, colistin is effective in vitro against multidrug-resistant $P$. aeruginosa [28-30]. Therefore, we evaluated the bacteriostatic and bactericidal effects of aztreonam, a 3-drug combination (aztreonam, ceftazidime and amikacin) and colistin against 23 strains of MBL-producing $P$. aeruginosa. We found that although aztreonam had relatively low MIC $(\leq$

Table 3: Antimicrobial effects of colistin ( $2 \mathrm{mg} / \mathrm{l})$ against 23 strains of metallo- -lactamase-producing $P$. aeruginosa

\begin{tabular}{ccc}
\hline & \multicolumn{2}{c}{ No. of strains (\%) showing effects ${ }^{\mathrm{a}}$} \\
\cline { 2 - 3 } Time of exposure $(\mathrm{h})$ & Bacteriostatic effects & Bactericidal effects \\
\hline 2 & $23(100)$ & $23(100)$ \\
4 & $23(100)$ & $23(100)$ \\
6 & $23(100)$ & $23(100)$ \\
24 & $23(100)$ & $23(100)$ \\
\hline
\end{tabular}

aBacteriostatic effects, any decrease in the viable count from the starting inoculum; bactericidal effects, $\geq 3 \mathrm{log} \mathrm{cfu} / \mathrm{ml}$ decrease in the starting inoculum. 


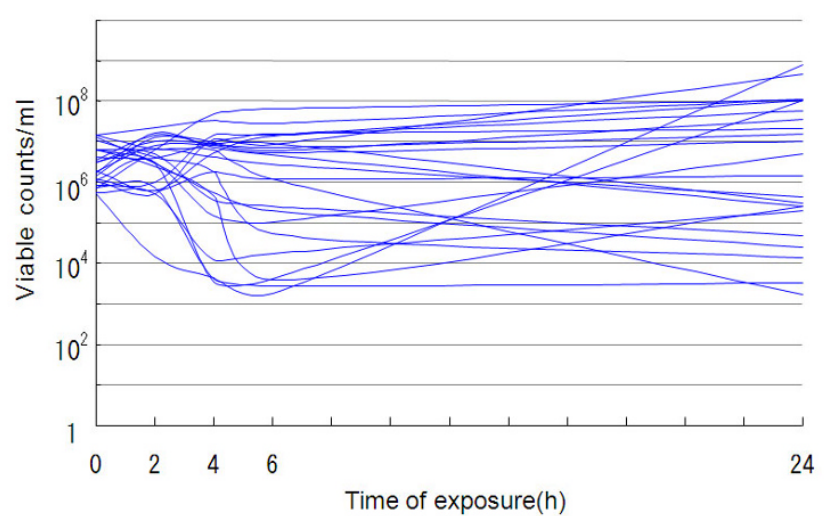

Figure I

Bactericidal effects of $\mathbf{4 8} \mathrm{mg} / \mathrm{l}$ aztreonam against 23 strains of metallo- -lactamase-producing $P$. aeruginosa $\left(37^{\circ} \mathrm{C}\right)$.

$64 \mathrm{mg} / \mathrm{l}$ ) among -lactam antimicrobial agents against 21 of the 23 strains of MBL-producing $P$. aeruginosa [additional file 1] the drug at 3-fold the breakpoint concentration, $48 \mathrm{mg} / \mathrm{l}$, had bactericidal effects only on 1 of the 23 strains when used alone (Table 1 ).

On the other hand, the 3-drug combination of aztreonam, ceftazidime and amikacin showed bacteriostatic effects against 19 (82.6\%) of the 23 MBL-producing strains and bactericidal effects against 7 (30.4\%) of the 23 strains at 6 $\mathrm{h}$ after drug addition, indicating relatively good in vitro antimicrobial effects. Therefore, the combination of the 3 drugs should be considered as a treatment method for infection with MBL-producing $P$. aeruginosa.

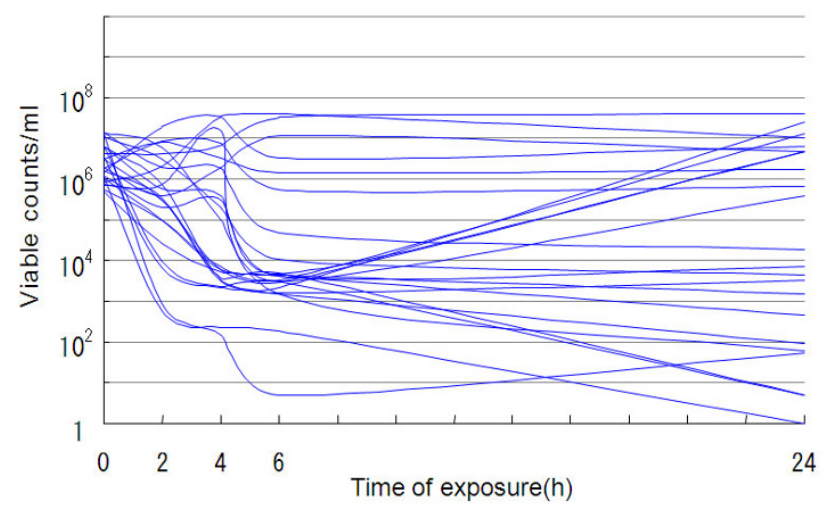

Figure 2

Bactericidal effects of the 3-drug combination of 16 $\mathrm{mg} / \mathrm{l}$ aztreonam, $16 \mathrm{mg} / \mathrm{l}$ ceftazidime and $4 \mathrm{mg} / \mathrm{l}$ amikacin against 23 strains of metallo- -lactamase-producing $P$. aeruginosa $\left(37^{\circ} \mathrm{C}\right)$.

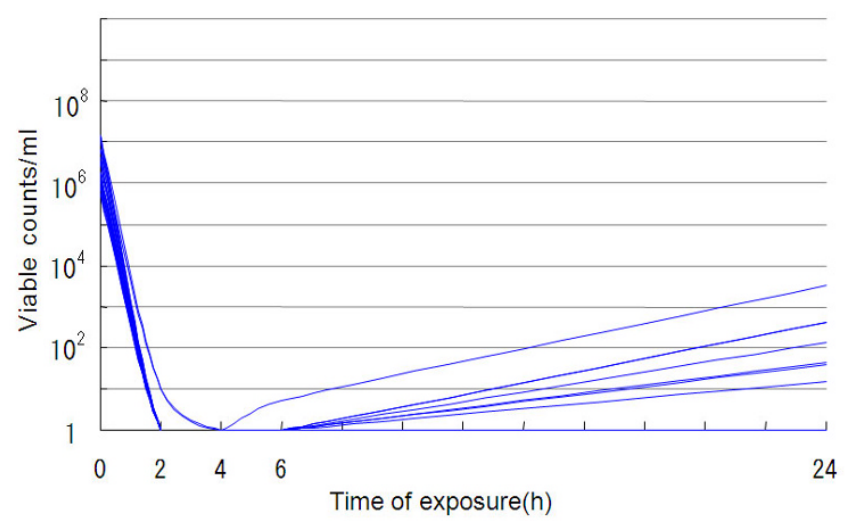

Figure 3

Bactericidal effects of $2 \mathrm{mg} / \mathrm{L}$ colistin against 23 strains of metallo- -lactamase-producing $P$. aeruginosa $\left(37^{\circ} \mathrm{C}\right)$.

Colistin had more marked in vitro antimicrobial effects than that of the 3-drug combination against MBL-producing $P$. aeruginosa, showing bactericidal effects against all 23 strains at $2-24 \mathrm{~h}$ after drug addition. Although colistin has severe side effects such as renal damage [31,32], some studies showed the clinical effectiveness of colistin against multidrug-resistant $P$. aeruginosa $[28,29]$.

\section{Conclusion}

Evaluation of in vitro antimicrobial effects on metallo- lactamase-producing $P$. aeruginosa revealed relatively good effects of the 3-drug combination of aztreonam, ceftazidime and amikacin and marked effects of colistin.

\section{Competing interests}

The authors declare that they have no competing interests.

\section{Authors' contributions}

SO and KA conceived the idea for the study; YF, MY, and YM collected the data; SO and KA drafted the manuscript. All authors contributed in the writing and preparation of the manuscript. All authors read and approved the final manuscript.

\section{Additional material}

\section{Additional file 1}

Table S1 MICs ( $\mathrm{mg} / \mathrm{l})$ of 11 drugs against 23 strains of metallo- $\beta$ lactamase-producing Pseudomonas aeruginosa. The data provided the MICs of the 11 drugs against the 23 strains of MBL-producing P. aeruginosa.

Click here for file

[http://www.biomedcentral.com/content/supplementary/14712334-9-123-S1.doc] 


\section{Acknowledgements}

We thank Yoshichika Arakawa, a director of Department of Bacterial Pathogenesis and Infection Control, National Institute of Infectious Disease for the kind donation of MBL-producing $P$. aeruginosa strains and for useful suggestions. We also thank Teruko Nakazawa, an emeritus professor at Yamaguchi University, and Tetsuya Matsumoto, a professor at Tokyo Medical University, for useful suggestions.

\section{References}

I. Thuong M, Arvanite K, Ruimy R, Salmonière $P$, Scanvic-Hameg $A$ Lucet JC, Régnier B: Epidemiology of Pseudomonas aeruginosa and risk factors for carriage acquisition in an intensive care unit. J Hosp Infect 2003, 53:274-282.

2. Lockhart SR, Abramson MA, Beekmann SE, Gallagher G, Riedel S, Diekema DJ, Quinn JP, Doern GV: Antimicrobial resistance among gram-negative bacilli causing infections in intensive care unit patients in the United States between 1993 and 2004. J Clin Microbiol 2007, 45:3352-3359.

3. Rossolini GM, Mantengoli E: Treatment and control of severe infections caused by multiresistant Pseudomonas aeruginosa. Clin Microbiol Infect 2005, I I: 17-32.

4. Karlowsky JA, Draghi DC, Jones ME, Thornsberry C, Friedland IR, Sahm DF: Surveillance for antimicrobial susceptibility among clinical isolates of Pseudomonas aeruginosa and Acinetobacter baumannii from hospitalized patients in the United States, 1998 to 200 I. Antimicrob Agents Chemother 2003, 47:I68I-I688.

5. Livermore DM: Multiple mechanisms of antimicrobial resistance in Pseudomonas aeruginosa : Our worst nightmare? Clin Infect Dis 2002, 34:634-640.

6. Garberding J, Gaynes R, Horan T, Abshire J, Alonso-Echanove J, Edwards J: National nosocomial infections surveillance (NNIS) system report, data summary from January 1990May 1999 (issued June 1999). Am J Infect Control 1999, 27:520-532

7. Sofianou D, Tsakris A, Skoura L, Douboyas J: Extended high-level cross-resistance to antipseudomonal antibiotics amongst Pseudomonas aeruginosa isolates in a university hospital. Antimicrob Chemother 1998, 40:740-742.

8. Oie $S$, Uematsu $T$, Sawa A, Mizuno H, Tomita M, Ishida S, Okano $Y$, Kamiya A: In vitro effects of combinations of antipseudomonal agents against seven strains of multidrug-resistant Pseudomonas aeruginosa. I Antimicrob Chemother 2003, 52:9| I-9|4

9. Oie S, Sawa A, Kamiya A, Mizuno H: In-vitro effects of a combination of antipseudomonal antibiotics against multidrugresistant Pseudomonas aeruginosa. J Antimicrob Chemother 1999, 44:689-69l.

10. Maeda K, Kobayashi Y, Oie S, Ishida S, Okano Y, Kobayashi T, Shikichi $\mathrm{K}$, Mizuno $\mathrm{H}$, Kamiya A: Antimicrobial effects of drugs against multidrug-resistant Pseudomonas aeruginosa. Biol Pharm Bull 2008, 31 : 1898-1901.

II. Walsh TR, Toleman MA, Poirel L, Nordmann P: Metallo- $\beta$-lactamases: the quiet before the storm? Clin Microbiol Rev 2005 I 8:306-325.

12. Sibata N, Doi Y, Yamane K, Yagi T, Kurokawa H, Shibayama K, Kato $\mathrm{H}$, Kai K, Arakawa Y: PCR typing of genetic determinants for metallo- $\beta$-lactamases and integrases carried by gram-negative bacteria isolated in Japan, with focus on the class 3 integron. J Clin Microbiol 2003, 41:5407-54I3.

13. Murray BE, Singh KV, Markowitz SM, Lopardo HA, Patterson JE Zervos MJ, Rubeglio E, Eliopoulos GM, Rice LB, Goldstein FW, et al.: Evidence for clonal spread of a single strain of $\beta$-lactamaseproducing Enterococcus (Streptococcus) faecalis to six hospitals in five states. I Infect Dis 1991, 163:780-785.

14. National Committee for Clinical Laboratory Standards: Methods for Dilution Antimicrobial Susceptibility Tests for Bacteria that Grow Aerobically, Approved Standard M7-A2. 2nd edition. Villanova, PA: NCCLS; 1990.

15. Soussy CJ, Cluzel R, Courvalin P: Definition and determination of in vitro antibiotic susceptibility breakpoints for bacteria in France. Eur J Clin Microbiol Infect Dis 1994, I 3:238-246.

16. Giamarellos-Bourboulis EJ, Kentepozidis N, Antonopoulou A, Plachouras D, Tsaganos T, Giamarellou H: Postantibiotic effect of antimicrobial combinations on multidrug-resistant Pseudomonas aeruginosa. Diagn Microbiol Infect Dis 2005, 5 I : I I3- I I 7.
17. Rochon-Edouard S, Pestel-Caron M, Lemeland J-F, Caron F: In vitro synergic effects of double and triple combinations of $\beta$ lactams, vancomycin, and netilmicin against methicillinresistant Staphylococcus aureus strains. Antimicrob Agents Chemother 2000, 44:3055-3060.

18. Giamarellos-Bourboulis EJ, Grecka P, Giamarellou H: In-vitro interactions of DX- a new carbapenem, meropenem and imipenem with amikacin against multiresistant Pseudomonas aeruginosa. J Antimicrob Chemother 8739, 38:287-29I.

19. Hallander HO, Dornbusch K, Gezelius L, Jacobson K, Karlsson I: Synergism between aminoglycosides and cephalosporins with antipseudomonal activity: interaction index and killing curve method. Antimicrob Agents Chemother 1982, 22:743-752.

20. Rasmussen BA, Bush K: Carbapenem-hydrolyzing $\beta$-lactamases. Antimicrob Agents Chemother 1997, 41:223-232.

21. Bellais $S$, Mimoz O, Léotard S, Jacolot A, Petitjean O, Nordmann P: Efficacy of $\beta$-lactams for treating experimentally induced pneumonia due to a carbapenem-hydrolyzing metallo- $\beta$ lactamase-producing strain of Pseudomonas aeruginosa. Antimicrob Agents Chemother 2002, 46:2032-2034.

22. Horimoto H, Morimoto $\mathrm{T}$, Kakimoto S: Clinical study of penetration of aztreonam into serum and pleural effusion. Chemotherapy (Tokyo) 1993, 4I:573-575.

23. Mizuta M, Linkin DR, Nachamkin I, Fishman NO, Weiner MG Sheridan A, Lautenbach E: Identification of optimal combinations for empirical dual antimicrobial therapy of Pseudomonas aeruginosa infection: potential role of a combination antibiogram. Infect Control Hosp Epidemiol 2006, 27:4|3-4I5.

24. Drago L, Vecchi ED, Nicola L, Colombo A, Guerra A, Gismondo MR: Activity of levofloxacin and ciprofloxacin in combination with cefepime, ceftazidime, imipenem, piperacillin-tazobactam and amikacin against different Pseudomonas aeruginosa phenotypes and Acinetobacter spp. Chemotherapy 2004, 50:202-210

25. Chen YH, Peng CF, Lu PL, Tsai JJ, Chen TP: In vitro activities of antibiotic combinations against clinical isolates of Pseudomonas aeruginosa. Kaohsiung J Med Sci 2004, 20:26I-267.

26. Giamarellos-Bourboulis EJ, Grecka P, Giamarellou H: Comparative in vitro interactions of ceftazidime, meropenem, and imipenem with amikacin on multiresistant Pseudomonas aeruginosa. Diagn Microbiol Infect Dis 1997, 29:8I-86.

27. Gerceker AA, Gurler B: In-vitro activities of various antibiotics, alone and in combination with amikacin against Pseudomonas aeruginosa. I Antimicrob Chemother 1995, 36:707-7 II.

28. Berlana D, Llop JM, Fort E, Badia MB, Jódar R: Use of colistin in the treatment of multiple-drug-resistant gram-negative infections. Am J Health-Syst Pharm 2005, 62:39-47.

29. Timurkaynak F, Can F, Azap ÖK, Demirbilek M, Arslan H, Karaman SO: In vitro activities of non-traditional antimicrobials alone or in combination against multidrug-resistant strains of Pseudomonas aeruginosa and Acinetobacter baumannii isolated from intensive care units. Int J Antimicrob Agents 2006, 27:224-228

30. Linden PK, Kusne S, Coley K, Fontes P, Kramer DJ, Paterson D: Use of parenteral colistin for the treatment of serious infection due to antimicrobial-resistant Pseudomonas aeruginosa. Clin Infect Dis 2003, 37:e I54-60.

31. Levin AS, Barone AA, Penco J, Santos MV, Marinho IS, Arruda EA, Manrique El, Costa SF: Intravenous colistin as therapy for nosocomial infections caused by multidrug-resistant Pseudomonas aeruginosa and Acinetobacter baumannii. Clin Infect Dis 1999, 28:1008-1011.

32. Evans ME, Feola DJ, Rapp RP: Polymyxin B sulfate and colistin: old antibiotics for emerging multiresistant gram-negative bacteria. Ann Pharmacother 1999, 33:960-967.

\section{Pre-publication history}

The pre-publication history for this paper can be accessed here:

\section{http://www.biomedcentral.com/1471-2334/9/123/pre} pub 